\title{
¿Es actual la filosofía política de Ralph Miliband? Algunas propuestas en torno al laborismo, el estado y la democracia
}

\author{
Is Ralph Miliband's Political Philosophy currently valid? \\ Some proposals on labour, state and democracy
}

RAFAEL RODRÍGUEZ PRIETO*

Resumen: Ralph Miliband fue uno de los principales representantes del pensamiento marxista en la última parte del siglo $\mathrm{XX}$, en especial por su análisis del partido laborista, el estado, el análisis de clase y la participación política. Analizo si sus trabajos continúan siendo influyentes en el siglo XXI. Trazo una breve semblanza del desarrollo de su pensamiento sociológico e identifico tres temas claves (la crisis del laborismo, el estado en la sociedad capitalista y la democracia socialista). Los examino y evalúo. El trabajo finaliza con una reflexión crítica sobre la actualidad del legado de Miliband.

Palabras clave: marxismo, democracia, laborismo, neoliberalismo, estado.

\begin{abstract}
Ralph Miliband was a leading contributor to the development of Marxist theory of the state in the late twentieth century, particularly on the labour party, state, class analysis and political participation. I analyse if his writings remain influential in twenty-first century. I trace briefly the development of Miliband's sociological thought and identifies three key themes and debates. I examine and evaluate the central themes in Miliband's work: the crisis of labourism, the state in the capitalist society and democratic socialism. The paper finishes with a critical reflection on Miliband's legacy.
\end{abstract}

Keywords: marxism, democracy, labourism, neoliberalism, state.

"Entre la justicia y mi madre, opto por mi madre"

Albert Camus

\section{Introducción}

El nombramiento de Gordon Brown como Primer Ministro, en sustitución de Tony Blair, devolvió el apellido Miliband a la actualidad periodística del Reino Unido. David Miliband, destacado colaborador de Tony Blair, fue designado jefe de la política exterior del gabinete

Fecha de recepción: 21/09/2015. Fecha de aceptación: 06/09/2016.

* Universidad Pablo de Olavide. Subdirector del Laboratorio de Ideas y Prácticas Políticas, rrodpri@upo.es. Actualmente trabaja sobre relaciones de poder en Internet y filosofía política contemporánea. Ha publicado recientemente el libro Poder e Internet. Un análisis crítico de la Red (Cátedra, 2016-con Fernando Martínez) y ha coordinado el libro colectivo Videojuegos. La explosión digital que está cambiando el mundo (Héroes de papel, 2016). 
de Brown. Después de la derrota laborista de mayo de 2010, David compitió con su hermano menor, Edward o Ed -como es conocido popularmente- por el liderazgo de los laboristas. Esta carrera por la sucesión de Brown finalizó con la elección de Ed como líder del laborismo en Manchester y candidato a Primer Ministro. Finalmente, fue derrotado por David Cameron y abandonó su puesto como líder del laborismo británico. David y Ed son hijos de Ralph Miliband, uno de los sociólogos e intelectuales marxistas más relevantes de la historia de Gran Bretaña. Su protagonismo en los años de la New Left fue extraordinario. Criticó tanto el socialismo real de la URSS (en el que perdió definitivamente su confianza después de los sucesos de Checoslovaquia), como la hegemonía capitalista. Entre sus obras más destacadas se encuentran: Parliamentary Socialism: A Study of the Politics of Labour (1961), The State in Capitalist Society (1969), Marxism and Politics (1977), Capitalist Democracy in Britain (1982), Class Power and State Power (1983), Divided Societies: Class Struggle in Contemporary Capitalism (1989) y Socialism for a Sceptical Age (1994)1.

Ralph Miliband tuvo una dilatada carrera por universidades de Gran Bretaña, EE.UU. y Canadá. Hijo de emigrantes judíos, trabajó en centros como la London School of Economics o la Universidad de Brandeis, donde el profesor David G. Gil le recuerda por su coherencia e interés en los colectivos sociales del área de Boston. Terminaría recalando en la City University de Nueva York, una de las instituciones educativas más críticas de los EE.UU. Se autodenominaba como un sociólogo marxista independiente. El marxismo era un marco de análisis, pero no una biblia. En Marxism and Politics señala, refiriéndose a un análisis marxista de los problemas que aquejan a países empobrecidos, que las categorías marxistas deberían aplicarse partiendo de la experiencia y singularidad del lugar y, en consecuencia, algunas podrían ser tomadas en cuenta y otras modificadas e incluso descartadas (Miliband, 1997, 15-16).

En Miliband observamos tanto la reflexión teórica reposada como el compromiso con los problemas de su sociedad y del mundo, como se reflejó en su debate sobre el estado de Israel con su amigo Marcel Liebman (Achcar, 2006, 65)². Redactó profundos estudios en las décadas de los setenta y ochenta justificando las razones por las que el laborismo británico se podría convertir en una opción política verdaderamente transformadora. Una idea que repitió con vehemencia fue que el Partido Laborista no era realmente un partido socialista, ya que los revisionistas habían alcanzado los centros de decisión (Miliband, 1964, 348-349). Ralph Miliband mantuvo hasta su último libro -corregido en la cama del hospital donde falleció- la necesidad de reformas profundas en materia económica y social, que dotaran a la ciudadanía de poder y limitaran la influencia de las corporaciones. Presentó su alternativa bajo la idea de democracia socialista y concentró gran parte de su pensamiento en la necesidad de avanzar hacia un modelo de economía mixta, que acabara con la influencia de las grandes corporaciones y respetara los derechos fundamentales. Otra de las contribuciones relevantes de Miliband fue el estudio de la teoría del estado.

1 El presente estudio se enmarca dentro del proyecto de investigación de excelencia RASEGUR, Plan Nacional de I+D+I (Ref.: DER2015-65906-P) y de la Red de Excelencia del Plan Estatal de Investigación Científica y Técnica y de Innovación 2013-2016 (DER15-69273-RED).

2 Miliband y Liebman sostuvieron un interesante debate sobre Israel, cada uno con posiciones diferentes, pero desde la coincidencia que les otorgaba tanto su militancia socialista como su procedencia. Finalmente, ambos adoptaron la tesis de los dos estados. 
Toda esta labor teórica se completa con la fundación junto con John Saville de la revista The Socialist, Register, que aún continúa publicándose bajo la codirección de uno de sus discípulos, Leo Panitch.

Sin embargo, su legado intelectual parece haber quedado olvidado. La publicación de una biografía (Newman, 2002) y de un volumen colectivo (Wetherly, 2007) o el acto de la LSE, en el que se presentó la biografía citada, con la intervención de personalidades como Anthony Giddens, Mary Kaldor, Leo Panitch, Tony Benn o Hilary Wainwright, son magras muestras de las raquíticas referencias que, en los últimos años, hemos podido encontrar del sociólogo británico. Recientemente, se ha publicado un estudio sobre su debate con Poulantzas (Barrow, 2016) ${ }^{3}$.

Este trabajo se propone analizar el pensamiento político de Miliband; una reflexión política y social desarrollada, sobre todo, a lo largo de los setenta y ochenta. Interesa además la posible contribución de su legado intelectual a la triple crisis actual que engloba a la socialdemocracia, al estado y a la representación política.

\section{El legado de Ralph Miliband: laborismo, estado y democracia}

El 18 de septiembre de 2014 se celebró un referéndum sobre la independencia de Escocia. Una de las principales bazas que jugaron los nacionalistas fue la promesa de revertir en el nuevo estado las políticas neoliberales aplicadas en los últimos decenios en Escocia. Meses después, el "brexit" significó la victoria de un nacionalismo que garantizaba la "tierra prometida" fuera de la UE, aprovechando la frustración social después de años de depauperización de la clase trabajadora. Ambos son salidas erradas a un doble malestar social vinculado tanto a políticas neoliberales como al desencanto con la socialdemocracia. Movimientos nacionalistas de diverso cuño han aprovechado para reconducir parte del cuerpo electoral a sus posiciones. El propio auge de Trump en EE.UU., el lepenismo o el golpismo de los nacionalistas en Cataluña son muestra de ello.

La crisis de los partidos socialdemócratas europeos comenzó en los setenta con divisiones internas, incapacidad para evitar el paro, y el consiguiente empobrecimiento de la clase trabajadora, o el desprecio a los movimientos sociales que les conminaron a llevar a cabo procesos de participación más profundos (Rodríguez Prieto, 2012). Durante toda su vida, Ralph Miliband reivindicó, tanto la resistencia al capitalismo en el laborismo, como la necesidad de diálogo fluido en el seno del partido. Aparte de su breve pertenencia al Partido Laborista, no militó en ninguna otra organización política (Ali, 2015, xi). En un célebre debate con Robert McKenzie en 1958, Miliband reclamó la democratización del partido con la finalidad de fortalecerlo (Panitch, 2001). Miliband denunció la influencia de las tesis del capitalismo contemporáneo, desarrolladas sobre las teorías neocontractualistas de la justicia o del pensamiento comunitarista, y la consiguiente erosión del socialismo en los partidos

3 Como señala Barrow, a pesar de tales diferencias que mantuvieron y propiciaron la discusión, producto de su pertenencia a diferentes escuelas y del ambiente "althusseriano" de la Europa continental, ambos coinciden en la crítica al estado como expresión de los intereses capitalistas. Cabría señalar que ambas visiones pueden ser complementarias. A esta conclusión ha llegado una de las obras más recientes dedicadas al debate; además ambos autores reivindicaron la importancia de que el marxismo analizara con rigor el estado, cosa que desde Lenin no había sucedido (Barrow, 2016, xii y 2). 
que debían representar tal opción. La impronta de pensadores liberales como John Rawls, en intelectuales pertenecientes a las órbitas de partidos socialdemócratas europeos es un buen ejemplo. Miliband analizó el pensamiento del profesor de Harvard y las críticas de los comunitaristas. Nuestro autor señala que aunque los comunitaristas reprocharon a Rawls que abstrajera al individuo del orden social, no contemplaron siquiera algo incluso peor: la invisibilización que hace Rawls de un orden social que se sustenta en la dominación y en la explotación (Miliband, 1997, 36). La crítica de la distribución no debería servir para obviar la gran relevancia que la producción tiene en la conformación del orden social. No se puede decir que una propuesta política pueda ser transformadora o social si obvia la influencia a todos los niveles de los grandes conglomerados económicos típica del capitalismo avanzado (Miliband, 1989, 231).

Miliband anticipó que la erosión de las posturas socialdemócratas y su travestismo en un laborismo reformista, convertido en un agente conservador dedicado a frenar las demandas de la clase trabajadora, traería graves consecuencias. La aceptación acrítica de la racionalidad capitalista significó una apuesta radical contra cualquier política que supusiera un cambio de sociedad. Para Miliband el laborismo británico se centró en respuestas inmediatas a coyunturas específicas, junto con el no cuestionamiento del orden establecido (Miliband, 1983, 291-192). Con sus renuncias, la socialdemocracia quedaba en una posición muy delicada. Por un lado, debía constantemente pugnar con lo que fue su tradición para ser aceptada plenamente en la globalización; no dejar ninguna duda de que aceptaba el credo neoliberal y que no cuestionaba los fundamentos del estado pluralista. Pero por otro, debía lidiar con la sangría de votos y apoyos. Con una brecha entre sus posiciones y el electorado potencial, que les hacía desperdiciar gran parte de su capital simbólico y apoyo popular.

\subsection{La crítica de Miliband al laborismo británico: laborismo sin socialismo}

Ralph Miliband comienza su último libro con una aseveración que resume su posición crítica con el laborismo: "el capitalismo constituye actualmente un obstáculo de grandes proporciones para la resolución de los males que ha producido su propio desarrollo" (Miliband, 1997, 5). De esta frase el autor británico desarrolla una propuesta cimentada en la idea de que la hegemonía capitalista debe acabar en beneficio de una alternativa socialista. La microracionalidad capitalista debe ser suspendida en beneficio de la macroracionalidad de la sociedad (Miliband, 1997, 17). A juicio de nuestro autor la macroracionalidad debe ser impulsada por un partido verdaderamente socialista y transformador.

Miliband siempre criticó el laborismo por carecer de un proyecto verdaderamente socialista. El autor británico creía que el socialismo no tenía nada de lo que avergonzarse. Justo lo contrario que la derecha. Miliband, que vivió directamente la II Guerra Mundial, denunciará con acidez como al día de hoy todo el mundo se considera demócrata, pero recuerda que ha habido muchos respetables ciudadanos que se han expresado en un tono autoritario o semiautoritario a propósito del nazismo y el fascismo en Gran Bretaña. Conservadores, derecha, e incluso destacados periodistas o miembros de la nobleza no ocultaron su simpatía por unos gobiernos que imponían la ley y el orden y combatían sin dudar el socialismo (Miliband, 
1982, 47-53)4. En la Europa de entreguerras se favorecieron, o al menos se entendieron como un mal menor, movimientos totalitarios que atacaron los ideales representados por la Revolución Rusa. El caso de Alemania ilustra bien este hecho. La represión del movimiento obrero en el interior precede a una crisis institucional que coincide con la minusvaloración del nazismo. En el resto de Europa no sólo no se condenaba el nazismo de forma abierta, sino que se podrían encontrar defensores y partidarios de Hitler.

En Miliband observamos tanto un orgullo por el socialismo y su historia, como una puesta en duda, cuando no crítica abierta, de las políticas laboristas de su tiempo. Desde su perspectiva, la estrategia del laborismo adolecía de un cierto complejo frente a la derecha y la aceptación de un sentido común capitalista perjudicial para la mayoría de la población. Este sentido común capitalista debe ser analizado desde la óptica gramsciana.

Siguiendo al intelectual italiano, la hegemonía, en su sentido actual, es la capacidad de la clase dirigente de inculcar sus valores a las clases subordinadas -convertirlos en el sentido común de la época- y hacerles creer que sea cual sea su diagnóstico del orden social, éste no puede ser mudado, pues no existe ninguna alternativa al mismo (Rodríguez y Seco, 2010). Miliband defendió que el orden instaurado se basaba más en la mera resignación que en el consenso (Miliband, 1997, 15-16). A su juicio, los bandazos ideológicos dados por el laborismo británico, al que nunca consideró verdadero socialismo, lo hacían presa de un nuevo revisionismo que condenaba su acción política. De acuerdo con Newman, este nuevo revisionismo, denunciado por nuestro autor, se inspiraba en tres aspectos fundamentales: la influencia de las políticas thatcheristas, la desastrosa experiencia soviética y la irrupción de nuevos movimientos sociales (Newman, 2002, 278 y ss.). Para Miliband este nuevo revisionismo evitaba que el laborismo ofreciera una alternativa real y de izquierda y consolidaba la vieja tradición del Partido Laborista de no ofrecer una alternativa real al capitalismo. Además erosionaba la centralidad de la clase trabajadora como motor de la transformación en beneficio de un postsocialismo que Miliband siempre censuró.

En su ensayo Class and party, Miliband concreta estas tesis y sitúa el debate sobre partido y clase social en dos coordenadas muy importantes. La primera es la necesidad de la intervención humana en la liquidación del capitalismo. Éste, a pesar de sus contradicciones, no caerá sin que la clase obrera se organice para ello. Es por ello imprescindible una organización bien engrasada, puesto que las adversidades y los oponentes de los trabajadores son amplios y poderosos (Miliband, 2004, 123). No se trataría de invocar un debate estéril entre organización y espontaneidad, sino en ofrecer una alternativa creíble y fiel a unos valores estructurados alrededor de la justicia social. La conclusión final de su diagnosis se resume en una propuesta: una profunda e imprescindible renovación del laborismo consistente en un fortalecimiento del socialismo y de sus bases marxistas.

Pero la posición de Miliband fue objeto, al mismo tiempo, de crítica por parte de sectores del propio laborismo que entendieron que su enfoque no era el correcto ${ }^{5}$. El historiador Eric

4 De hecho, hubo un intento por parte de los tabloides sensacionalistas - en concreto el Daily Mail- de erosionar el liderazgo de su hijo Ed. Se sacaron de contexto unas declaraciones de Ralph Miliband y se le calificó como "una hombre que odiaba su propio país". Hubo una reacción que se articuló tanto en la falta del veracidad de la acusación, como en el apoyo del propio periódico al fascismo antes de la II Guerra Mundial (Ali, 2015, xii)

5 Newman señala que durante los años 1983 y 1984 sostuvo este debate tanto en el ámbito público como privado -con su amigo Hobsbawm. La amistad entre ambos se resintió de manera evidente. 
Hobsbawm publicó en 1978 un trabajo titulado The forward march of labor halted? en el que revisaba la evolución de la clase trabajadora en los últimos cien años. Las principales ideas que expresó en ese estudio se pueden resumir en los siguientes puntos:

1. Hubo una creciente estratificación y división entre trabajadores con un declive de la conciencia de clase social, lo que se tradujo en una disminución de la sindicalización y del apoyo a partidos de izquierda como el laborista y el comunista.

2. El resultado fue que gran parte de la clase trabajadora perdió la fe en los partidos de masa dirigidos a la clase trabajadora.

3. En consecuencia, era necesario moderar las políticas que se ofrecían al electorado y establecer una alianza estratégica de centro izquierda contra el thatcherismo.

Como señala Newman, el historiador se alineó con aquellos sectores del laborismo que propugnaban un abandono del "bennismo"-muy combativo con Thatcher- y la construcción de una coalición moderada de fuerzas contrarias a primera ministra británica (Newman, 2002, 278).

Miliband respondió con vehemencia a esta tesis, aunque sin citar expresamente a Hobsbawm. Para Miliband el problema no era que hubiera desaparecido la clase trabajadora o que el laborismo se hubiera escorado demasiado a la izquierda. La cuestión era que la deriva derechista del partido había erosionado la calidad de vida de los potenciales votantes. Además, el auge de los movimientos sociales, partidarios de una mayor profundización en los valores de izquierda, habían colisionado con la dirección de un partido que sentía la influencia de estos colectivos como una erosión de su autoridad. Como consecuencia de ello, el Laborismo concurría a las elecciones con una dirección inmovilista y enfrentada a los movimientos sociales. Debemos señalar que aunque Miliband consideraba relevante el papel de estos últimos, continuaba considerando a la clase obrera como central para cualquier cambio. Es más: siempre fue precavido en lo que se refiere a evaluar el potencial revolucionario y los objetivos de dichos colectivos a los que consideraba incapaces de llevarlos a cabo por sí mismos. Miliband observó siempre con recelo la apelación a la identidad, iniciada en las décadas de los sesenta y setenta (Moran, 2015) y era conservador en cuestiones como las relaciones sexuales y drogas, que habían seducido a buena parte de los movimientos contestatarios de su época. Cuando el 68 fracasó a manos de la derecha, no se sorprendió (Burnham, 2008, 34-35). Nuestro autor siempre intuyó que eran estériles como mecanismos de cambio real y fácilmente asimilables al capitalismo.

Miliband realizó varias intervenciones públicas en las que insistió en que la oposición no era un mal escenario, si los colectivos podían hacerse con el partido y dar coherencia a las propuestas de la dirección y al programa con el que se concurriría a las elecciones (Newman, 2002, 279). Pero sus tesis no fueron escuchadas en el seno del laborismo; Miliband se distanció del partido de manera notable. El Laborismo moderó su discurso, pero aun así permaneció en la oposición hasta que la descomposición del thatcherismo se hizo evidente de la mano de John Major. Un joven Tony Blair terminó por consolidar el viaje del laborismo hacia la aceptación de las bases ideológicas del neoliberalismo.

La propuesta del new labour consistió en acomodar el estado a las exigencias de la globalización. La propuesta era adaptar los gobiernos a las nuevas circunstancias de la era global, lo que significaba que éstos debían aprender de la eficiencia de las empresas 
(Giddens, 1999, 91). Se dio la espalda a la clase, entendida de acuerdo a cómo la sociedad organiza la producción, apropiación y distribución de plusvalía (Wolf y Resnich, 2002, xi). El evidente incremento de la brecha entre rentas de trabajo y de capital supuso la erosión de la socialdemocracia. Al final, los ingentes costes y pérdidas de la banca fueron pagadas por los contribuyentes (Wolf, 2012, 73). Los estados que partían de una desventaja mayor -países del sur de Europa como España- han padecido más que otros del norte el crecimiento de las rentas del capital en detrimento de las del trabajo o la brecha salarial entre los mejor y peor pagados (Navarro, 2013).

El proceso apuntado por Miliband, de plena actualidad por los recortes sociales, nos muestra que el modelo de estado pluralista, liderado por una socialdemocracia que ha traicionado a su electorado, no sólo no ha resistido el empuje de las tesis neoliberales, sino que además ha favorecido la destrucción de buena parte de las conquistas sociales propiciadas por el pacto de postguerra que dio lugar al estado del bienestar. Miliband apuntó en su célebre análisis del Estado capitalista, que estudiaremos en el siguiente epígrafe, a esta cuestión.

\subsection{La crítica al estado pluralista}

El núcleo de la tesis de Miliband sobre el estado se centra en el análisis y crítica del enfoque pluralista. Los defensores de esta perspectiva -por ejemplo, un autor tan relevante como Isaiah Berlin- mantienen que el poder se encuentra fragmentado y abierto a la libre competencia política. De acuerdo a esta noción del estado, la sociedad industrial ha permitido que la condición de obrero se transforme gracias a la meritocracia y la movilidad entre los diversos estratos de la pirámide social. La igualdad de oportunidades, la pluralidad de intereses económicos de las elites y la competencia entre capital y trabajo completan esta visión del estado. Este enfoque ha tenido muy destacados críticos. Bottomore señaló, en línea con Miliband, que la igualdad de oportunidades presupone una desigualdad, puesto que oportunidad significa la posibilidad de elevarse a un nivel superior en una sociedad estratificada. La igualdad de oportunidades sólo será realizable en una sociedad sin clases ni élites (Bottomore, 1995, 157). En este sentido, Marx y Engels describían su sociedad como aquella en que el $10 \%$ de los habitantes era dueño de los medios de producción. Hoy esta cifra ha caído hasta el 1\%. Actualmente, al menos entre el 45\%-60\% de la ventaja social por riqueza pasa de padres a hijos (McChesney, 2013,27). La escasa movilidad económica implica que sean las mismas familias las que por generaciones ocupen los puestos decisivos de poder económico y político en la sociedad capitalista, con escasas y excepcionales variaciones. Como se ha publicado recientemente, existe un `suelo de cristal que protege generación tras generación a las rentas altas. El estudio empírico de Barone y Mocetti (2016) así lo ha puesto de manifiesto para el caso de Florencia, aunque por las circunstancias de esta ciudad, los investigadores lo consideran extrapolable al mundo occidental.

En El Estado en la sociedad capitalista, el sociólogo británico estudia el origen social de quienes militan en la gerencia y aquellos que cuentan con altos ingresos y propiedades. El enfoque pluralista, que trataba de disociar ambos, carecería según Miliband de base real: tanto managers como propietarios están plenamente de acuerdo en la reproducción del orden capitalista. El pluralismo de élites significa que la diversidad de elites de la sociedad capitalista constituye una clase económica dominante con un alto grado de cohesión y 
solidaridad entre sus miembros, capaz de trascender cualquier diferencia puntual entre los mismos (Miliband, 1976, 268). Esta conexión entre clase dominante y estado es denominada por Miliband como un "partnership" (Miliband, 1983, 72-74). Este concepto equivale a un acuerdo en el que las partes cooperan para llevar a cabo un fin común.

Miliband señala que cuando la socialdemocracia europea ha alcanzado el poder ha dedicado bastante tiempo y esfuerzo a mostrar su adhesión al modelo capitalista. Su tarea era concebida desde una perspectiva nacional, no de clase y, por consiguiente, la elite empresarial podía estar tranquila con el nuevo gobierno (Miliband, 1976, 97 y 110) ${ }^{6}$. Miliband considera que la clase dirigente posee e influye en medios de producción material y mental, lo que les permite ejercer un control directo sobre el estado. El estado capitalista se convierte en instrumento de la clase dominante, ya que la élite administrativa y judicial comparte su ideología y objetivos. El poder económico privado presiona estableciendo límites estructurales que reducen la acción de cualquier gobierno (Miliband, 2004, 75-77). Este análisis se corresponden con dinámicas muy conocidas y difundidas en los últimos años, como la "puerta giratoria" -el último caso ha sido el de Durao Barroso- o el cada vez más indisimulado poder de las grandes empresas en el gobierno de los estados y de las organizaciones de integración regional -como la UE-, a través de lobbies o contribuciones a los partidos políticos. La tendencia que apuntó Miliband, hace décadas, parece haber pasado la prueba de la historia y la experiencia práctica.

La posición instrumentalista de Miliband, centrada en poner las promesas del estado liberal pluralista frente a sus contradicciones y a sus falsedades, fue criticada por Poulantzas. Para el autor griego, la metodología de Miliband es errónea, ya que los hechos extraídos de las experiencias que refiere Miliband, deben ser combatidos por otros conceptos alternativos. El sociólogo británico responde a esta crítica acusando a Poulantzas de no atender a los hechos y encerrarse en un abstraccionismo estructuralista que le impedía analizar la realidad histórica. Subrayar de forma excesiva las relaciones objetivas conduce a un superdeterminismo estructural que imposibilita cualquier estimación realista de la relación entre el estado y el sistema (Miliband, 1993, 26) 7 .

La conclusión de Miliband es que el estado en el capitalismo es necesario para el desarrollo y reproducción de un modelo social que consolida una relación de desigualdad entre clases sociales. Un modelo que se ha hecho más sofisticado con el proceso de globalización y la revolución tecnológica. El debilitamiento de los estados, aunque no su desaparición de la escena como actores decisivos en los procesos de legitimación de la reproducción del modelo capitalista, junto con el reforzamiento de las corporaciones transnacionales, ha beneficiado procesos de integración regional -UE- y la consolidación de organizaciones multilaterales como la OMC. Estos procesos han conducido a que incluso a sectores liberales, defenso-

6 La amplia victoria laborista de después de la II Guerra Mundial no significó un cambio en el sistema de poder y privilegios. Miliband señala que los laboristas contaron con un apoyo masivo que desaprovecharon.

7 Como señala Duhalde, para Miliband y Poulantzas el concepto de "clase dominante" sintetiza la relación entre un conjunto de intereses diferentes, aunque convergentes. El diferente enfoque de uno y otro autor se plasmaría en que para Miliband esta clase estaría conformada por diferentes "élites económicas" -poniendo el acento en los individuos que las integran y en las acciones de los mismos sobre las condiciones del capital y sobre el estado. Para Poulantzas estaría integrada por "fracciones de capital", otorgando de esta manera un peso decisivo a la dimensión objetiva, y diferenciando estas fracciones no por las acciones de los sujetos sino por los intereses objetivos establecidos en el modo de producción capitalista (Duhalde, 2008). 
res de la visión pluralista del Estado, los critiquen porque erosionan la legitimidad de los parlamentos y acrecientan la brecha entre representantes y representados. Esta situación ha mostrado una democracia capitalista, cada vez más capitalista y menos democrática, contra la que han reaccionado movimientos como Occupy o el 15M en España. En el siguiente epígrafe estudiaremos la propuesta democrática de Miliband centrada en la idea de democracia socialista.

\subsection{La democracia socialista}

Para Miliband la democracia, entendida como proyecto de emancipación, no presupone el capitalismo como modo de producción. De esta manera, el autor británico se situó más allá del pactismo socialdemócrata de corte reformista, pero también del socialismo real soviético. Su propuesta para transformar las relaciones sociales en occidente la denominó "democracia socialista". En su último libro defiende la tesis de que la democracia capitalista es una contradicción en términos (Miliband, 1997, 41). Desde esta perspectiva, el socialismo tiene dos objetivos: (i) democratizar la sociedad más allá de los límites de la democracia representativa y (ii) atenuar la inmensa desigualdad existente en nuestras sociedades, con el establecimiento de un modelo productivo sustentado en un programa de renovación social radical (Miliband, 1997, 202).

Pero no será fácil. Miliband señala que la mayor parte de la izquierda ha aceptado un conservadurismo epistémico, cultivado por la derecha, sobre lo que es posible o no. No se pueden negar los problemas que engendra una construcción socialista; se trataría, más bien, de ofrecer respuestas y soluciones a los mismos. Hay tres argumentos recursivos de los inmovilistas: (i) el ingenuo optimismo respecto a las capacidades humanas para autoorganizarse y cooperar; (ii) la "ley de hierro de las oligarquías" y (iii) el problema ecológico.

Miliband replica de dos formas al primero. Por un lado, el socialismo no pretende proporcionar una solución perfecta a los problemas de la humanidad; por otro lado, si echamos un vistazo a la historia, es sencillo percatarse de que las grandes carnicerías nunca han sido resultado de una acción puramente espontánea desde abajo. La falsa noción de "todos somos culpables" enmascara la realidad. Han sido las minorías gobernantes las que han diseñado y organizado matanzas masivas. No es una fantasía pensar que los crímenes colectivos e individuales bajo condiciones sociales distintas pudieran convertirse en un fenómeno marginal (Miliband, 1997, 68-72). La segunda dificultad sería la denominada por Michels "ley de hierro de las oligarquías". El socialismo aspira a que el poder se distribuya con el fin de generar un genuino autogobierno. Las teorías elitistas niegan esta posibilidad. Para superar este obstáculo será necesario que cambie el contexto económico, social, político y moral en el que se ejerce el poder. Si los ciudadanos son más iguales y más conscientes de sus derechos, es más complicada la oligarquización (Miliband, 1997, 73-75). El tercer argumento que frenaría las expectativas socialistas sería el de los problemas ecológicos que han surgido en las últimas décadas y que han propiciado perspectivas neomathusianas y ecologistas. Miliband cuestiona este tipo de aproximaciones simplistas a problemas de extraordinaria complejidad. El autor británico se pregunta hasta qué punto los problemas mediomabientales pueden ser resueltos en un contexto de hegemonía de los imperativos capitalistas. El socialismo propondría atacar el problema ecológico de raíz (Miliband, 1997, 75-76). 
En cualquier caso, para Miliband, los cambios no están exentos de problemas como el propio Marx puso de manifiesto, mediante la idea de que eran inevitables defectos en la primera fase de la nueva sociedad. Hay que ser realistas y distinguir entre lo que se puede esperar a corto y mediano plazo y a largo plazo, con generaciones educadas en un sentido común diferente que prime la cooperación, el igualitarismo, la democracia y la sociabilidad (Miliband, 1997, 78). El también sociólogo David Gil, colega de Miliband en Brandeis University, se sitúa en una posición semejante. Cuando en su teoría de la justicia social analiza la idea de cambio afirma que para evitar desmanes es imprescindible ser pacientes y entender que los cambios profundos no se dan de un día para otro, sino que implica procesos a largo plazo (Gil, 2008).

Democracia, igualdad y cooperación son los principios éticos sobre los que debe pivotar el socialismo. El hecho de que un puñado de personas se apropie de los recursos y de los medios de producción es una injusticia social inadmisible para Miliband. Como señala en su obra Divided Societies, el desarrollo del capitalismo contemporáneo se materializa en un enorme poder sobre los recursos ejercido por un número muy reducido de individuos, lo que implica situarse en una posición estratégica para el control de la sociedad (Miliband, 1989, 213).

Miliband no subestima al capitalismo. Es consciente de las resistencias que una transformación real de la sociedad encontrará. En su compilación de artículos publicada en 1983 bajo el título Class Power \& State Power -y reeditada en 2015 con un prólogo de Tariq Ali- Miliband diferencia entre lucha de clases y guerra de clases. Cuando los hombres con poder real creen que confrontan una amenaza relevante desde abajo, toman decisiones excepcionales que implican diferentes estrategias de lucha. Este nuevo conjunto de iniciativas se identifican con la guerra de clases, puesta en marcha cuando la amenaza afecta a pilares fundamentales del sistema. Chile había conocido la lucha de clases en el marco de las democracias capitalistas; con la llegada de Allende las fuerzas conservadoras convirtieron la lucha de clases en guerra de clases (Miliband, 82-83). Para ilustrar el apoyo que los golpistas tuvieron en el exterior, trae a colación una editorial del diario The Times en el que se llegaba a decir que las circunstancias eran tales que un militar razonable podría haber pensado de buena fe que su deber constitucional era intervenir (Miliband, 1983, 80-81). Una vez más se repitió en Gran Bretaña algo similar a lo visto con Hitler.

El control de los medios claves en la economía se traduce en influencia política y apoyo mediático. Por tanto, el proceso político y participativo que propone Miliband no tendría sentido sin un cambio a nivel económico. Para nuestro autor, el socialismo tiene en la abolición del trabajo asalariado su meta. Lo probable es que sea un proceso largo. La sociedad no es tan fácilmente maleable como pensaron algunos marxistas. El socialismo constituiría un nuevo orden social marcado por continuidades y discontinuidades. Para Miliband la democracia socialista implica tanto la extensión de la capitalista, como su superación. Esta extensión y superación se fijaría en dos grandes renovaciones: la que afecta a la participación de los ciudadanos en la política o la reforma del estado y los cambios en el modelo productivo. Ambas para Miliband son interdependientes e imprescindibles (Miliband, 1997, 81).

Miliband plantea una reforma del estado que, mediante una serie de cambios institucionales, condujera a la democracia socialista. Considera que algunos elementos del liberalismo -principio de legalidad, la separación de poderes el pluralismo político, la sociedad civil 
activa- deberían permanecer en una democracia sin capitalismo. Se incluiría la separación de poderes y se prestaría especial atención a la formación de las personas para participar activamente en el autogobierno del estado. En lo que respecta a la organización administrativa estatal, era partidario de un equilibrio entre poder central y periferia y de sistemas proporcionales de representación (Miliband, 1997, 89-94).

Miliband se oponía a la concentración de poder. La democracia socialista censuraría cualquier proceso de culto a la personalidad y fomentaría la devolución de responsabilidad en la gestión de los asuntos públicos, a las organizaciones de base. En el resto de los sectores de la sociedad -fábricas, oficinas y lugares de trabajo- se apostaría por un control sustentado en la participación y gestión activas, en la medida de lo posible, de los trabajadores que se encuentran en ellas (Miliband, 1997, 94-97).

Miliband afirmó que "la banca y las finanzas son asuntos demasiado serios para dejarlos a merced de banqueros y financieros". Hay que impedir que este sector obstaculice las medidas de renovación social legitimadas por el proceso democrático. La desaparición del control empresarial sobre los principales medios de la actividad económica significaría una transformación radical de la misma. El principio organizador de una economía socializada sería la satisfacción de necesidades individuales y colectivas. Las prioridades para la satisfacción de las mismas serían determinadas democráticamente (Miliband, 1997, 117 y 139). Miliband apuesta por la autogestión y la democratización de la producción, a la vez que recrimina a los partidos socialdemócratas su rechazo de la nacionalización; a su juicio, no es la solución mágica a los problemas, pero puede ser una herramienta adecuada en determinadas circunstancias. Su negación absoluta significa que los partidos socialdemócratas han abandonado la posibilidad de realizar una transformación profunda. Todo ello es consecuencia del clima de hostilidad generado contra cualquier experiencia de propiedad pública. El giro ideológico en la izquierda implicó un desarme de la misma y de sus propuestas. El sociólogo británico cita trabajos en que se demuestra de forma fehaciente que la empresa pública puede ser tan eficiente como la privada. Una economía socializada constaría del sector público, -predominante y variado-, sector cooperativo -sustancial y en expansión$\mathrm{y}$, finalmente, el de la propiedad privada compuesto principalmente por pymes (Miliband, 1997, 104 y ss.). Miliband no condena la empresa privada; lo que pretende limitar es la influencia y poder de las grandes corporaciones.

En definitiva, nuestro autor desarrolla una idea de democracia que va más allá de un enfoque reduccionista. Pretende extender la participación a todas las esferas de la vida y, al mismo tiempo, no caer en los errores del socialismo real. La propuesta de Miliband es una posibilidad, que como los análisis del estado y de laborismo contiene elementos que pueden inspirarnos en el análisis de los desafíos actuales y en la búsqueda de estrategias que nos permitan caminar hacia una sociedad mejor.

\section{3. ¿Es actual el legado intelectual de Miliband?}

Los temas centrales de la obra de Miliband crecen en interés si observamos la forma en que se han desarrollado los procesos sociales en las últimas décadas. El estudio de sus aportaciones críticas al laborismo, la teoría del estado o la democracia nos permite extraer una serie de tesis que debemos contrastar con los procesos sociopolíticos contemporáneos 
en Europa a fin de evaluar la actualidad de su pensamiento político. Los recortes sociales refuerzan las tesis de Miliband, que demostró empíricamente la existencia de clases y los mecanismos que facilitan la cohesión económica de los capitalistas y su vinculación con el estado (Barrow, 2016, 23).

La primera de la tesis apunta directamente a la rendición de los partidos socialdemócratas. Los partidos socialdemócratas han entrado en un proceso evidente de asunción de las tesis neoliberales. Las políticas de recorte del gasto público y privatización de otros partidos socialdemócratas del norte y del sur de Europa atestiguan esta dinámica de forma fehaciente. De esta carencia de proyecto se contagiaron también los partidos comunistas (Rodríguez, 2013, 44). Los graves problemas económicos generados por la especulación financiera y los recortes en los derechos sociales han provocado graves tensiones en Europa que se han reflejado a su vez en una crisis de los partidos socialdemócratas. El descontento de una mayoría de los ciudadanos con sus instituciones y con sus políticos es hoy un síntoma evidente de que algo no funciona bien. Los partidos socialdemócratas han defraudado las expectativas del electorado. En vez de defender el estado del bienestar han optado por asumir el discurso de las privatizaciones y los recortes. En Francia, el descontento ha sido reconducido hacia el voto ultranacionalista que representa por el Frente Nacional; en España o el Reino Unido lo ha sido, en parte, hacia movimientos separatistas o populistas.

La posición de Miliband, en torno a la necesidad de que los partidos de la izquierda asumieran un programa realmente transformador, ha sido uno de los elementos que más controversia generó en sus días. Esta cuestión continua vigente. La pregunta se plantearía en términos de si los partidos de izquierda pierden apoyo electoral por ser demasiado de izquierdas o justo por lo contrario. Para Miliband, la renuncia de los partidos socialdemócratas a un ideario transformador los condenaba a que su electorado potencial les diera la espalda.

Esta idea no ha podido ser falsada por la realidad de los últimos años. Los partidos socialdemócratas han perdido elecciones y afiliados. La crisis del partido conservador post-thatcher fortaleció al laborismo, pero de manera ilusoria, hasta que un candidato joven destronó al gobierno de Gordon Brown en 2010. En el caso de España, el PSOE ha obtenido los peores resultados de su historia en las últimas elecciones generales.

El desengaño del electorado laborista ha provocado abstención o fuga de votos a otras opciones. Las políticas del nuevo laborismo -en realidad el triunfo de las tesis de Howsbawn- implicaron un progresivo descenso del apoyo. El 43.2\% de la primera elección dejó paso a un $35.3 \%$ de la última y al descenso y estancamiento con Brown y Ed Miliband. Solo un candidato del ala izquierda del partido -Corbyn- pudo el 8 de junio de 2017 alterar esta tendencia con un $40.3 \%$, lo que en cierta medida constituye un refrendo de las ideas de nuestro autor.

El descrédito de la socialdemocracia puede también explicar el auge de movimientos como el 15M, cuyo surgimiento tiene lugar con un gobierno del PSOE, que había participado en la reforma del art. 135 de la Constitución Española. Un vistazo a sus propuestas nos muestra un ideario transformador que se sitúa en una dinámica antagónica a las políticas aplicadas por partidos socialdemócratas en las últimas décadas. Si además añadimos la implicación de políticos socialdemócratas en la construcción de una Europa neoliberal desde el Colegio de Comisarios, se comprende con mayor claridad el desencanto de un buen número de ciudadanos con la UE y con estos partidos. La consecuencia de todo ello es que 
Miliband hizo el análisis correcto. Sólo con partidos socialdemócratas que prometan y, sobre todo, actúen de forma que se desarrolle la justicia social, se logrará un apoyo parlamentario y extraparlamentario que los fortalecerá.

La segunda tesis se centra en la presunta neutralidad del estado y su consideración como factor decisivo en la promoción de los intereses capitalistas. El estado pluralista ha agudizado los problemas que Miliband detectó en su trabajo de $1969^{\circ}$. Preocupaciones como la puerta giratoria -revolving door- o la creciente influencia de los lobbies a nivel estatal y supranacional, son muestra de ello. El caso de Goldman Sachs y su influencia en los gobiernos de occidente ha salido a la palestra con motivo de la crisis financiera. Políticos directamente implicados en la gestión de la misma como Lucas Papademos, primer ministro de la Grecia desde el 2011, han trabajado para Goldman. Otros casos famosos son los de Robert Rubin, Robert Zoellick o Romano Prodi, aunque son sólo unos ejemplos, ya que existe un elevado número de casos.

La tercera tesis es la necesidad de desarrollar un modelo democrático que profundice en la participación en todas las áreas y niveles. Ya en 1994, el propio Miliband puso sobre la mesa uno de los actuales problemas de la Unión Europea, cuando se refirió a las limitaciones que cualquier estado miembro de esta organización tendría que afrontar. El hecho de que en Europa se propusiera un Banco Central y una moneda única ejemplificaba según Miliband el compromiso de la construcción europea con la agenda neoliberal. Esta alianza se traducía en que el gobierno económico y financiero futuro no sería elegido por los ciudadanos y podrían sustraerse de controles democráticos (Miliband, 1997, 202-203). Desgraciadamente las predicciones de nuestro autor no han podido ser falsadas por la realidad. Los ciudadanos perciben la democracia como un rito periódico incapaz de contrarrestar un nivel de desencanto creciente (Navarrete, 2013). La propuesta de Miliband se centraría en la participación radical y en la democratización del aparato productivo como pilares esenciales de cualquier transformación. Estas ideas se encuentran muy cerca de las propuestas que colectivos críticos como el 15M llevaron a las plazas y a las redes sociales en 2011 y que hoy parecen muy lejanas.

Un balance de la actualidad del pensamiento político de Miliband nos arrojaría dos conclusiones: por un lado es un trabajo imprescindible para comprender las dinámicas del Estado pluralista y su conexión con el capitalismo en los tiempos de la globalización; por otra parte, sus tesis pueden ayudarnos a encontrar vías de análisis de los retos actuales.

\section{Conclusiones: Ralph frente a Ed en 2016}

Quizá, si Ralph Miliband volviera a la tierra en 2017 no se llevaría demasiadas sorpresas, si exceptuamos las relativas a la familia y al avance tecnológico. Probablemente no se asombraría mucho de la evolución de los partidos socialdemócratas en Europa. Como hemos estudiado, ya analizó esta tendencia en varios de sus estudios y éstas sólo se han agudizado en el siglo XXI. La participación de políticos de dichos partidos en las políticas neoliberales

8 El sentido final de la obra de Miliband fue explicar por qué un estado nominalmente democrático respondía a los intereses las élites capitalistas en vez de a los de la inmensa mayoría de la ciudadanía (Barrow, 2016, 6) y la unidad de los capitalistas, por encima de credos y naciones, es una fuente explicativa destacada. 
de la UE ha sido una consecuencia lógica de la conversión neoliberal de sus propios partidos políticos. El crecimiento de la desigualdad y el alejamiento de los ciudadanos de la política han sido los efectos previsibles. El imaginario encuentro entre padre -intelectual marxista-y su hijo -frustrado líder laborista- ejemplifica con gran nitidez la brecha que se ha abierto en Europa entre una posición que ha transigido con las tesis neocontractualistas de la justicia y otra que las criticó con rigor.

Observaría un mundo donde el significante "crisis económica" no es más que una argucia para ocultar una nueva acumulación de capital, ligada a una devaluación salarial. Le llamaría la atención que las pérdidas provocadas por la burbuja financiera hayan sido, en primera instancia, socializadas y, posteriormente, convertidas en una crisis de deuda. Probablemente sonreiría con amargura al recordar sus estudios sobre el estado al ver un gráfico de la evolución de la deuda pública española antes y después del salvamento de la banca. Sin duda se interesaría por el uso que se hace de ella para forzar la privatización de servicios públicos. Quizá se sorprendería del grado en que se han recortado derechos sociales en toda Europa en los últimos años, especialmente después de la aprobación del Tratado de Lisboa o de la situación griega después del referéndum y el giro a la derecha de Syriza.

Como han puesto de manifiesto autores no socialistas, pero muy críticos con las consecuencias de este proceso, actualmente los Estados ya no son soberanos, sino juegan a serlo, que es diferente, mientras que el individuo es adoctrinado en una enfermiza desconfianza, cuyo núcleo central se resume en que es razonable ser egoísta. Los criterios de eficiencia de la cadena de montaje fordista se han trasladado a lo social y a la constitución de un estado de mercado de la información a imagen de la evolución y necesidades del capitalismo contemporáneo (Schirrmacher, 2014, 237).

Los parlamentos nacionales pierden competencias en beneficio de instancias escasamente sujetas al escrutinio ciudadano. El desarrollo y evolución de la UE ha dado la razón a Miliband. Su análisis del estado en la sociedad capitalista no sólo no ha perdido vigencia sino que además sus tendencias se han agudizado. El creciente uso de la puerta giratoria, que une altos responsables del estado a directivos de altas empresas, la composición de los entes supranacionales diversos como la UE o la OMC no permiten falsar el pensamiento de Miliband que cuestiona la neutralidad del análisis pluralista. Estos vicios pueden ser aplicados a la UE. La influencia de lobbies o la cesión de políticas monetarias al BCE son muestras de un parlamentarismo reducido.

En respuesta a ello, la idea de la democracia socialista de Miliband podría ser una herramienta factible de cambio. No se trata de vetar instituciones que unan Europa, sino que éstas representen los intereses de la mayoría de la ciudadanía. Los procesos democráticos y de participación deben servir para construir una sociedad europea justa y democrática. Esta democracia se sustentaría en (i) la idea de poder constituyente como proceso inmanente de conocimiento de la realidad desde las condiciones materiales; (ii) la idea de hegemonía como condición para la transformación de la sociedad, desde los planos simbólico, desde el plano socio-económico y tecnopolítico (construcción y acceso al conocimiento, aprovechando los recursos que Internet pone a nuestra disposición); (iii) y la re-humanización de la sociedad fomentando relaciones significativas y cooperativas.

El análisis de Miliband está de plena actualidad en la medida que los acontecimientos actuales ha reforzado sus conclusiones y sus diagnóstico relativo a la transformación social. 
El mismo 15M coincidió en sus propuestas con algunas recetas que presentó décadas antes. Su enfoque transformador, comprometido con la clase social como categoría central, y las propuestas vinculadas al partido, estado y democracia permitirían construir una Europa sustentada en pilares como la justicia social, la utilidad social de la producción y la democracia.

Cuando un periodista afeó a Camus su falta de apoyo al FLN argelino éste contestó que entre la justicia y su madre, prefería a ésta última ${ }^{9}$. Camus fue, como Miliband, de los primeros en criticar tanto capitalismo como comunismo soviético. Un intelectual reacio a cualquier credo totalizador y excluyente. Un "génie libertaire" comprometido en la lucha contra la injusticia. Miliband nos muestra una vía política, que aunque distinta, sitúa lo humano y sus necesidades en su centro. Es el principal valor de un legado que permanece vivo.

\section{Referencias Bibliográficas}

Ali, T. (2015), Introduction, en Miliband, R. Class War, Conservatism and Other Essays. London: Verso.

Achcar, G. (ed.) (2006), The Israeli Dilemma. A debate between two left-wing jews. Letters between Ralph Miliband and Marcel Liebman. Monmouth, Merlin Press.

Barone G., Mocetti, S. (2016), Intergenerational mobility in the very long run:

Florence 1427-2011. Working Paper. Banca dÍtalia,1060 - April.

Barrow, C. W. (2016), Toward a Critical Theory of States: The Poulantzas-Miliband Debate After Globalization. New York: State University of New York Press.

Barrow, C. W. (2002), "The Miliband-Poulantzas Debate:An Intellectual History" Aronowitz, S. Bratsis, P. (ed.). Paradigm lost. State Theory Reconsiderated. Minneapolis, Minnesota University Press.

Bottomore, T. (1995), Élites y sociedad. Madrid, Talasa.

Duhalde, S. (2008), "Un debate epistemológico sobre el "Estado capitalista. La polémica Miliband Poulantzas". Kairos: Revista de temas sociales 21: http://philpapers.org/rec/ DUHUDE

Giddens, A. (1999), La tercera vía. La renovación de la socialdemocracia. Madrid, Taurus.

Giddens, A. (1996), Más allá de la izquierda y la derecha. El futuro de las sociedades radicales. Madrid, Cátedra.

Gil, D. (2008), Discurso de aceptación del Premio Noam Chomsky, Washington (cita tomada por el autor).

Gunn, S. (1989), Revolution of the Right. London, Pluto.

Hobsbawm, E. (1978), “The Forward March of Labour Halted?". Marxism Today. Consulta 12 de septiembre de 2012. (http://www.amielandmelburn.org.uk/collections/mt/ pdf/78_09_hobsbawm.pdf)

McChesney, R. W. (2013), Digital Disconnect. How Capitalism is turning the Internet Against Democracy. New York, The New Press.

Miliband, R. (2004), Marxism and Politics. London, The Merlin Press.

Miliband, R. (1997), Socialismo para una época de escépticos. México, Siglo XXI.

9 El FLN estaba llevando a cabo atentados en tranvías en Argel, lo que ponía en peligro a la madre de Camus. 
Miliband, R. (1989), Divided Societies. Class Struggle in Contemporary Capitalism. Oxford, Oxford University Press, Oxford.

Miliband, R. (1983), Class Power \& State Power. Political Essays. London, Verso.

Miliband, R. (1982), Capitalist Democracy in Britain. Oxford, Oxford University Press.

Miliband, R. (1976), El Estado en la sociedad capitalista. México, Siglo XXI.

Miliband, R. (1973), "The Coup in Chile". The Socialist Register 10: http://socialistregister. com/index.php/srv/issue/view/406\#.VCwdChbNlGZ

Miliband R. (1964), Parlamentary Socialism. A Study in the Politics of Labour, London, Merlin Press.

Moran, M. (2015), Identity and Capitalism, London: Sage.

Navarro, V. (2013), "El crecimiento de las desigualdades de rentas: causas y consecuencias". Revista digital Sistema 5 de julio.

Navarrete, R. (2013), "Análisis del Desencanto". Agenda Pública 22 de julio. Consulta 3 de septiembre de 2013 (http://www.eldiario.es/agendapublica/nueva-politica/Analisisdesencanto_0_156434823.html)

Newman, M. (2002), Ralph Miliband and the Politics of the New Left. London, Merlin Press.

Panitch. L., Leys, C. (2001), The End of Parlamentary Socialism. From New Left to New Labour, London, Verso.

Rodríguez, J. C. (2013), De qué hablamos cuando hablamos de marxismo.Teoría, literatura y realidad histórica. Mad rid, Akal.

Rodríguez Prieto, R. (2012), "De la socialdemocracia al socialiberalismo. La socialdemocracia en la encrucijada: declive, renuncias y alternativas. Anuario de Filosofía del Derecho, XXVIII.

Rodríguez Prieto, R. Seco Martínez, J. M. (2010), ¿Por qué soy de izquierdas? Por una izquierda sin complejos. Córdoba, Almuzara.

Wetherly, P., Barrow, C. W., Burnham, P. (ed.). (2007), Class, Power and the State in Capitalist Society. Essays on Ralph Miliband. London, Palgrave Macmillan.

Wolf, R. (2012), Democracy at Work. A Cure for Capitalism. Chicago, Haymarket Books.

Wolf y Resnich, (2002), Class Theory and History: Capitalism and Communism in the USSR. New York, Routledge. 